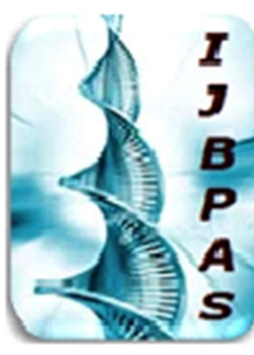

\author{
International Journal of Biology, Pharmacy \\ and Allied Sciences (IJBPAS) \\ 'A Bridge Betusen Caboratory and QRader'
}

WWW.ijbpas.com

\title{
BIOFLOC TECHNOLOGY: QUESTIONING THE COMPETENCE OF A LUCRATIVEFARMING METHOD
}

\author{
PRAKASH A \\ Fergusson College, Pune \\ *Corresponding Author: Dr. Anwesha Prakash: E Mail: prakashanwesha.81@gmail.com \\ Received $10^{\text {th }}$ June 2021; Revised $11^{\text {th }}$ July 2021; Accepted 20 ${ }^{\text {th }}$ Aug. 2021; Available online $15^{\text {th }}$ Jan. $_{2022}$
}

https://doi.org/10.31032/IJBPAS/2022/11.1.1003

\begin{abstract}
Aquaculture has always been an ever-expanding horizon, with new and sustainable farming methods emerging ever so frequently to increase overall efficiency and profitability. Biofloc Technology or BFT has been a comparatively new method of cultivation in this area to spark an interest in entrepreneurs. A fairly simple technology, it involves keeping varied microbial communities or Biofloc suspended in the waters and using methods like constant aeration and/or agitation, maintaining the $\mathrm{C} / \mathrm{N}$ ratio of the culture water so that toxic materials to the fish like nitrate, nitrite, ammonia, biological wastes, etc. can be converted into proteinaceous food.

Although this method may superficially seem very intriguing and promising for amateur farmers to gain quick profits, many unforeseen problems may arise, which might cause much greater losses than expected. Therefore, it becomes crucial that the sustainability and efficiency of this technology are critically examined, and this paper is an attempt to do so in this regard.

Keywords: Biofloc, Microbial communities, Aquaculture, Sustainable farming

INTRODUCTION:

One of the latest buzzwords among start-up aspirers, Biofloc Technology or 'BFT' has begun blooming in the agricultural landscape. Aimed at exponentially expanding

the horizon in aquaculture, BFT enhances the quality of cultivated water by elevating the $\mathrm{C} / \mathrm{N}$ levels of the aquaculture system through external sources (Ahmad I. et al., 2017). While this technology has been deemed as an
\end{abstract}


innovative and promising tool to improve aqua-cultural production, many issues may arise when the technology is used in a practical setting. From significantly large investments in the set-up, equipment, and other such nonrecurring expenditure to ensuring proper cultivation, a skilful and elaborate procedure has to be followed and along the way and an entrepreneur may face many problems that they did not anticipate as they had taken up the project. Hence, it is imperative that this technology is scrutinized with a hands-on approach to identify all possible difficulties that may appear along the way.

BFT is a relatively novel technology and more so for a town like Tezpur in Assam, India. The entrepreneurs who have taken up this method of aquaculture mostly rely on the internet and general recommendations from people who present it as "a new way to gain instant profits". There seems to be apaucity in understanding the technology and all of the hidden issues it may harbour. Therefore, the present work used samples from BFT farms in and around the town of Tezpur to explore some of the complications associated with this technology and question its competence in the Indian scenario.

\section{Objective:}

To check the sustainability of Biofloc Technology via the conduction of a survey across BFT farms in and around the town of Tezpur, Assam.

\section{An overview of the Biofloc Technology:}

Biofloc technology is an aqua-cultural method aimed at high-density pisciculture with minimal or no water exchange under strong aeration and biota formation (Avnimelech, 2009). An intensive technology, BFT involves maintaining flocs of microbial communities like heterotrophic bacteria, fungi, phytoplankton, etc. in the culture water which utilize carbon and nitrogen sources like molasses, unused feed, fish excreta, and convert them into proteinaceous feed. The greatest advantage Biofloc enthusiasts have over traditional methods of aquaculture is that BFT provides the farmers with a denser culture than the traditional ones in a much smaller area of land; so small that entrepreneurs can even begin profitable cultivations in their backyards too. The setup of the farm involves constructing tanks usually made out of polyethylene materials like tarp, supported by an iron mesh; and they can even be constructed using concrete and stainless steel.

The cultivation process starts with the phasewise preparation of the culture tanks. $\mathrm{KMnO}_{4}$ is used to clean the tanks and remove any unwanted microbes. After a thorough cleaning, water is added along with a constant supply of oxygen through air blowers so that the free 
radicals present get oxidized. Salt and calcium carbonate are added to provide a base for the growth of the floc and maintained according to the suitable $\mathrm{pH}$ parameters. Salt also helps in reducing the transportation and adaptation stress that the fish might have experienced. The next step involves the addition of varied microbial cultures via FCO or Fermented Carbon Organic which is a mixture of microbes, molasses and iodine-free salt (Singh R., 2020). Additional amounts of molasses are added for the cultures to proliferate and grow into flocs. After substantial growth of the floc, the fish seed is added and their growth period starts.

The flocs, supported by the continued addition of molasses and fish feed begin aerobic biodegradation of waste products like ammonia. This degradation produces proteins as they utilize nitrogen to form microbial biomass that can be used as food by the fishes. FCR or Feed Conversion Ratio, which is the amount of feed consumed by fish (g) to increase $1 \mathrm{~g}$ of fish weight, is ideally high and hence, reliance upon fish feed alone is lessened and the fish can grow up with less amount of food that had to be given otherwise (Maulid Wahid Y. et al., 2015).

The basic simplicity of the entire process, coupled with the sustainable and eco-friendly appeal is what attracts so many people to start cultivating in this method, but the number of problems that arise is often unexpected and the farmers have generally reported to experience major losses.

\section{METHODOLOGY:}

Based on the method of field survey, 24 BFT farms were selected in and around the town of Tezpur for the purpose and the farm owners and operators were interviewed with a questionnaire having both closed and openended questions, ranging from farm size to profit. Some of the questions were based on the Likert system having 5 to 7 point scales.

\section{Survey:}

\section{Farm size:}

The farms were selected at random for the survey and an average of 6 tanks were seen in every BFT farm and the average area occupied was around $125 \mathrm{~m}^{2}$ for the entire setup.

Table 1: Farm size

\begin{tabular}{|c|c|}
\hline Total volume of Water & No. of farms \\
\hline $\mathbf{1 0 , 0 0 0 - 3 0 , 0 0 0}$ & 14 \\
\hline $30,000-60,000$ & 6 \\
\hline $50,000-1,00,000$ & 0 \\
\hline Above 1,00,000 & 4 \\
\hline
\end{tabular}

Source: Field study

* Tank sizes range from 10,000 litres to 15,000 litres 


\section{Capital investment:}

Table 2: Capital investment

\begin{tabular}{|c|c|}
\hline Amount (in rupees) & Number of Farms \\
\hline $1,00,000-3,00,000$ & 1 \\
\hline $3,00,000-6,00,000$ & 6 \\
\hline $6,00,000-9,00,000$ & 8 \\
\hline $9,00,000$ and above & 9 \\
\hline
\end{tabular}

Source: Field study

The total expenditure was mostly These costs, especially the farms with heavy reported to be even more than the recorded investments ranging from $6,00,000$ to $9,00,000$ capital investment due to recurring and operational costs owing to various reasons.

rupees and above were majorly acquired via bank loans.

\section{Fish varieties:}

\begin{tabular}{|c|c|}
\multicolumn{2}{|c|}{ Table 3: Fish varieties } \\
\hline Fish & No. of farms \\
\hline Catla & 1 \\
\hline Rohu & $\mathbf{1}$ \\
\hline Singi(Stinging Catfish) & $\mathbf{2 0}$ \\
\hline Magur (Walking Catfish) & $\mathbf{2}$ \\
\hline Kawoi (Climbing Perch) & $\mathbf{6}$ \\
\hline Rupchanda (Red Pomfret) & $\mathbf{8}$ \\
\hline Pangasius & $\mathbf{0}$ \\
\hline Tilapia & \multicolumn{2}{|c|}{} \\
\hline
\end{tabular}

The major fishes in cultivation are throughout the year and their seed is easier to Singi and Kawoi. These fishes hold demand obtain in comparison to other fish seed.

\section{Seed and fish feed procurement:}

Table 4: Distances covered for seed and feed procurement

\begin{tabular}{|c|c|}
\hline Distance (in kilometres) & No. of farms \\
\hline $5-15$ & 0 \\
\hline $15-25$ & 2 \\
\hline $25-35$ & 7 \\
\hline $35-45$ & 9 \\
\hline 45 and above & 6 \\
\hline
\end{tabular}

Source: Field study

Seed refers to the culture of fishes in ensure minimum mortality due to their hatchling stages, especially fish fry and fingerling. In almost all the farms surveyed, to transportation stress, etc., fingerlings are used as seeds.

\section{Difficulties faced:}

Table 5: Issues faced

\begin{tabular}{|c|c|}
\hline Potential issues & Percentage of farms \\
\hline 1. Availability of constant electricity & $64 \%$ \\
\hline 2. Consistent growth of fishes & $75 \%$ \\
\hline 3. Culture affected due to diseases & $100 \%$ \\
\hline $\begin{array}{c}\text { 4. Culture affected due to natural calamities (storms, heavy } \\
\text { rains, etc.) }\end{array}$ & $68 \%$ \\
\hline 5. Easy availability of farm helpers and workers & $10 \%$ \\
\hline 6. Ease of food and seed procurement & $\mathbf{9 4 \%}$ \\
\hline
\end{tabular}

Source: Field study 


\section{Profit Margin:}

Table 6: Profits
\begin{tabular}{|c|c|}
\hline Profit (in percentage) & No. of farms \\
\hline $0-25$ & 17 \\
\hline $25-50$ & 4 \\
\hline $50-75$ & 3 \\
\hline $75-100$ & 0 \\
\hline
\end{tabular}

Source: Field study

\section{RESULTS AND DISCUSSION:}

Significant responses were received from 24/24 farms. As seen from the tables above, a plethora of issues have been reported and almost all of the farms have faced some or the other issue during BFT farming. For such heavy capital investments ranging from $3,00,000$ to $9,00,000$ rupees and above, the gains have been reported to be either very low or even diverging into losses. For instance, some of the visited farms have reported unnerving losses of as high as $90 \%$, making the contrast between the theoretical and practical application of this technology blatantly obvious. Very specific protocols and courses of action have to be followed for a successful culture and in this regard, majority of the farmers fail to follow such strict procedures. As a result, to tackle the issues that arise out of such improper management, they may try to incorporate their devised ideas or judgements from videos on the internet which have fairly negative outcomes. So the problem only aggravates further, instead.

One of the main issues reported was the supply of constant electricity to keep the aeration units running since the majority of these farms are situated in the countryside. Another major issue faced is the sensitivity to diseases. All farmers reported the high susceptibility of the cultured fish towards varied diseases, especially fungal diseases like fin rot, etc. which occur frequently with even the slightest weather changes; and the difficulty in controlling the diseases. An alarming $75 \%$ mortality in total culture fish has also been reported, the culprit being a fungal infestation.

The model fishes taken for this culture are tilapia, carp, salmon, etc. While these fishes have an established demand overseas, they either have no consumers or are too difficult to procure in Assam, India. Tilapia, specifically are the best adapted to BFT and were the first fish to be cultivated in Israel when this technology first began, as stated by Dr Yarom Avnimelech in his book "Biofloc technology. A practical guide book”, 2009. But here in India and especially in Assam, Tilapia has no market, and local fishes like Rohu, Catla, Singi, Magur etc. do not consume the flocs and have slow and/or stunted growth in this system. Because of this, the production cost increases, hampering the marketing and 
sales. Another issue in this regard that is worth mentioning is that the produce in these systems has very poor value and demand in the market. Locally referred to as 'Tank Fish', these fishes become abnormally difficult to sell to local sellers. The fact behind such peculiarly poor demand and sales is the general assumption that "tank fish" are inferior to fish harvested in natural water bodies. The rate in the market for Magur, for instance, is Rs. 1200 per $\mathrm{kg}$ for the naturally harvested and Rs. 300- 400 for Biofloc fish. Similarly for Singhi- Rs. 800 vs Rs 350-400, and Kawoi - Rs. 800 vs Rs. 150200.

Another disappointment voiced by many farmers is the inability to choose the kind of fish they want to cultivate. It has been reported that the choice of seedlings may be unavailable or too costly at the time of procurement and the farmers have had to go through a production lag phase for as high as 3 months before getting the preferred seeds.

The fish feed also has to be according to the fishes' age and size. For context, farmers reported the unavailability of proper feed for the growing fish, and they had to feed adult fish with $0.8 \mathrm{~mm}-1.0 \mathrm{~mm}$ feed. This feed, meant for the young growing fingerlings, is high in protein content and the adult fish tend to consume more of it which increases ammonia production due to more excretion and ultimately results in imbalances in the culture.

The lack of skilled to semi-skilled labourers is another problem faced. Since this method needs such intensive care and supervision, even the slightest mistake in feed amount, $\mathrm{C} / \mathrm{N}$ and $\mathrm{pH}$ level measurements can have adverse consequences for the cultured fish. (Avnimelech, 2009)

Another major issue that arises is algal blooms. Minor shifts in the $\mathrm{C} / \mathrm{N}$ levels in presence of sunlight causes rapid algal growth in the tanks forming a thick, net-like layer on the surface of the tank, reducing dissolved oxygen levels in the tank drastically and preventing air-breathing fish like Singi, Magur, etc. to obtain oxygen.

\section{Suggestions:}

While BFT does pose many problems along the course of cultivation, it still has potential as a fool-proof method. With more research, ways to increase efficiency in cultivating local fishes could be devised and achieved. Also, another suggestion would be to cultivate these fish as seed and sell them as bigger seed. For example, if cultivation starts in winter, they could be sold as bigger seed at the onset of spring for cultivation, especially in natural waters. As this would ensure the rapid growth of the fish for their buyers, with proper advertising, it can create a market for such 
biofloc cultured seeds. It is to be noted that at the fry and fingerling stage, every fish variety more or less consumes a certain amount of floc for nutrition.

It should also be noted that the capital investment over a due course of time gets compensated and even overtaken by the profits incurred, and since these farms are fairly new, they might have not yet reached that period. Hence, patience is the key and the farmers should not give up easily. More emphasis should be put upon this inevitable phase so that farmers are aware and ready for it.

\section{CONCLUSION:}

Although boasting many exemplary factors like eco-friendly, cost-effective, efficient land and water use, higher profits, etc., Biofloc may look very attractive on the surface, until the real-time problems begin overshadowing its initial appeal. In-depth knowledge is required and BFT aspirants should pick this method of farming up only after thoroughly understanding all the risks involved. Further research and development are a necessity to understand and combat these issues so that BFT can be tapped into its full potential.

\section{REFERENCES:}

[1] Irshad Ahmad I,Rani A. M. Babitha, Verma A.K., Maqsood M., 2017. Biofloc technology: an emerging avenue in aquatic animal healthcare and nutrition. Aquacult Int (2017) 25:1215-1226 DOI 10.1007/s10499-0160108-8.

[2] Maulid Wahid Yusuf, Nur Bambang Priyo Utomo, Munti Yuhana and Widanarni, 2015. Growth Performance of Catfish (Clarias gariepinus) in Biofloc-Based Super Intensive Culture Added with Bacillus sp.. Journal of Fisheries and Aquatic Science.DOI: 10.3923/jfas.2015.523.532

[3] Dr. Singh R., 2020. Basics Of Bioflock Fish/Aqua Culture.

https://www.pashudhanpraharee.com/basicsof-bioflock-fish-aqua-culture/. Retrieved on November 4th, 2021.

[4] Avnimelech, Y. (2009). Biofloc technology. A practical guide book. The World Aquaculture Society. Baton Rouge. 